\title{
Clinical, biochemical, and radiographic effects of aminohydroxypropylidene bisphosphonate treatment in rheumatoid arthritis
}

\author{
STUART H RALSTON, ${ }^{1}$ LINDA HACKING ${ }^{2}$ LORNA WILLOCKS,${ }^{1}$ \\ FIONA BRUCE, ${ }^{1}$ AND DENIS A PITKEATHLY
}

From the ${ }^{1}$ Medical Unit $A$ and the ${ }^{2}$ Department of Radiology, Southern General Hospital, Glasgow

SUMMARY A placebo controlled, double blind study of aminohydroxypropylidene bisphosphon- $-\dot{c}$ ate (APD), given by monthly intravenous infusion, was conducted in 40 patients with rheumatoid arthritis. Biochemical markers of increased bone resorption, such as fasting urinary calcium/ $\mathcal{I}$ creatinine ratio and hydroxyproline/creatinine ratio, were suppressed significantly in the $\mathrm{APD}_{-}^{-}$ group to approximately $50 \%$ and $60 \%$ of the pretreatment level respectively, and serum calcium fell transiently after the first APD infusion. There was no significant effect on disease activity in either the APD or placebo groups as judged by clinical (grip strength, morning stiffness, visua $\mathscr{C}_{\circ}^{\circ}$ analogue score) or laboratory (haemoglobin, platelet count, erythrocyte sedimentation rate, $\mathrm{C}$ reactive protein) criteria. An exception was the articular index which improved to a similaro degree in both groups, falling from (mean (SEM)) $13.8(1 \cdot 8)$ to $7 \cdot 2(2 \cdot 2)$ in the APD group ands from $13.7(1.9)$ to $6.8(1.5)$ in the placebo group. Radiological progression occurred to a similaro degree in both groups as assessed by the Sharp index (mean (SEM) 86 (13.1) v 95 (12.9)-APD group; $103(15 \cdot 1) v 110(15 \cdot 8)$ - placebo group), but there was no significant change in the Larsen index in either group (mean (SEM) $53(4.2) v 57(3.8)$-APD; $62(5.8) v 63(5.6)$-placebo). The lack of effect on radiological progression in the APD group indicates that focal erosive disease ${ }_{\supset}$ may either have progressed as the result of a non-osteoclast related mechanism, or that the intensity of bone resorption was too great to be inhibited by the doses of APD used. The biochemical response to APD presumably reflected inhibition of bone resorption at other sites, $\frac{\overline{2}}{\bar{\sigma}}$ suggesting that further studies of the effects of bisphosphates on periarticular and systemic osteoporosis in rheumatoid arthritis may be of interest.

Key word: osteoporosis.

Periarticular osteoporosis, bone erosions, and generalised osteoporosis are important features of rheumatoid arthritis. ${ }^{12}$ Current management of bone involvement in rheumatoid arthritis is unsatisfactory as disease modifying antirheumatic drugs seldom prevent progression of periarticular erosive disease $^{3}$ and do not protect against the development of generalised osteoporosis. ${ }^{4}$

Bisphosphonates, such as aminohydroxypropylidene bisphosphonate (APD), have been shown to be effective in inhibiting accelerated bone resorp-

Accepted for publication 22 September 1988.

Correspondence to Dr Stuart H Ralston, University Department of Medicine, Glasgow Royal Infirmary, 10 Alexandra Parade, Glasgow G31 2ER. tion in Paget's disease, ${ }^{5}$ hypercalcaemia of malignancy, ${ }^{6}$ primary hyperparathyroidism, ${ }^{7}$ steroid ${ }^{\mathrm{r}}$ induced osteoporosis, ${ }^{8}$ and metastatic cancer. ${ }^{9}$ We ${ }^{N}$ have now studied the clinical, biochemical, and radiographic effects of APD in patients witho rheumatoid arthritis.

Patients and methods

It was decided to limit the study to patients with rheumatoid arthritis who were already stabilised bys treatment with one disease modifying antirheumati迎 drug (penicillamine) plus or minus their usuab treatment of non-steroidal anti-inflammatory drugs and analgesics. Forty such patients were recruite 
from the general rheumatology clinic on a consecutive basis. All gave informed consent to participation in the study, which was also approved by the local hospital ethical committee. The patients were randomly allocated on a double blind basis to receive monthly intravenous infusions of either APD $30 \mathrm{mg}$ in $500 \mathrm{ml} 0.9 \%$ saline or a matching placebo, which were given over a two hour period on a day patient basis.

Biochemical and haematological measurements were made on blood and second voided 'spot' urine samples obtained after an overnight fast at each clinic attendance using standard automated techniques. Urinary calcium and hydroxyproline excretion were expressed as molar ratios relative to urinary creatinine. Serum calcium was adjusted for albumin as previously described. ${ }^{10}$ Erythrocyte sedimentation rate was determined by the Westergren method.

Clinical assessment was carried out by the same observer (SHR) in each patient monthly for the first three months, at six months, and again at 12 months. The following measures of disease activity in rheumatoid arthritis $^{11}$ were recorded: grip strength (dominant hand; mean of three readings), Ritchie articular index, and early morning stiffness. The patients' subjective assessment of joint pain and stiffness was recorded on a visual analogue scale

Table 1 Relevant clinical and laboratory variables in the study group. Values are mean (SEM)

\begin{tabular}{|c|c|c|}
\hline Variable & $\begin{array}{l}A P D^{*} \\
(n=20)\end{array}$ & $\begin{array}{l}\text { Placebo } \\
(n=20)\end{array}$ \\
\hline Age (years) & $60(2 \cdot 1)$ & $56(2 \cdot 7)$ \\
\hline $\operatorname{Sex}(M / F)$ & $7 / 13$ & $7 / 13$ \\
\hline Disease duration (years) & $6.9(1.2)$ & $6 \cdot 5(0 \cdot 8)$ \\
\hline Penicillamine dose (mg/day) & $537(45)$ & $562(59)$ \\
\hline $\begin{array}{l}\text { Duration of penicillamine treatment } \\
\text { (months) }\end{array}$ & $34(5 \cdot 5)$ & $31(6 \cdot 0)$ \\
\hline Haemoglobin $(g / 1) \dagger$ & $132(21)$ & $127(33)$ \\
\hline $\begin{array}{l}\text { Erythrocyte sedimentation rate } \\
(\mathrm{mm} / \mathrm{h}) \dagger\end{array}$ & & \\
\hline $\mathrm{C}$ reactive protein $(\mathrm{mg} / \mathrm{l}) \dagger$ & $27(10)$ & $33(9)$ \\
\hline Serum creatinine $(\mu \mathrm{mol} / \mathrm{l}) \dagger$ & $78(4 \cdot 8)$ & $73.5(4 \cdot 3)$ \\
\hline Serum alkaline phosphatase $(\mathrm{U} / \mathrm{I}) \dagger$ & $225(12 \cdot 2)$ & $224(15.0)$ \\
\hline Articular index & $13.8(1.8)$ & $13.7(1.9)$ \\
\hline Grip strength (mm) & $101(14)$ & $92(10)$ \\
\hline Morning stiffness (min) & 61 (14) & $51(10)$ \\
\hline
\end{tabular}

*APD=aminohydroxypropylidene bisphosphonate.

†Normal reference ranges: haemoglobin 115-175 g/l; erythrocyte sedimentation rate $<30 \mathrm{~mm} / \mathrm{h} ; C$ reactive protein $<10 \mathrm{mg} /$; serum creatinine $40-130 \mu \mathrm{mo} / /$; serum alkaline phosphatase 70-350 U/l. Note: By 24 weeks three patients in each group had withdrawn from the study owing to lack of effect, leaving 17 in each group. By 48 weeks a further four had dropped out from the placebo group and a further one from the APD group for similar reasons, leaving 13 patients in the placebo group and 16 in the APD group at the end of the study. (from $0=$ no joint pain or stiffness whatsoever to $10=$ joint pain and stiffness as bad as they could be). At each clinic visit patients were specifically asked about any adverse effects experienced since the previous visit. Radiological progression of joint disease was assessed on paired radiographs obtained immediately before starting treatment and again after 12 months. These were assessed by a radiolog-

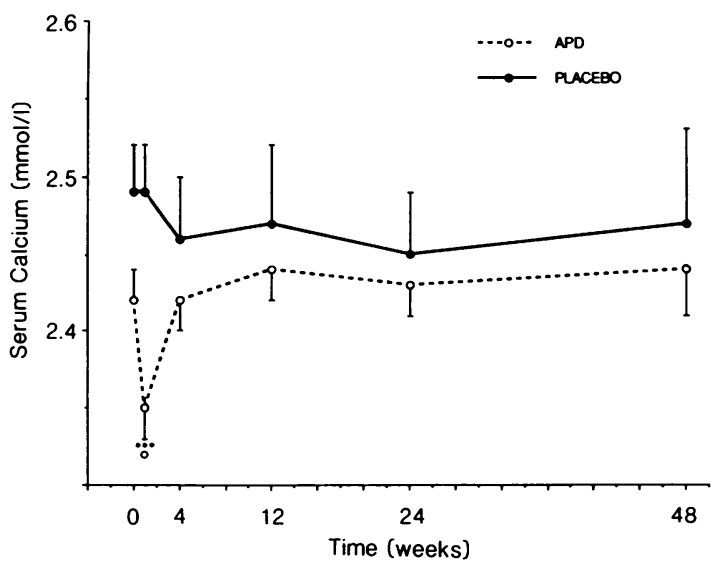

Fig. 1 Response of serum adjusted calcium values to treatment with aminohydroxypropylidene bisphosphonate $(A P D)$ and placebo. Points are means, bars are standard errors of the mean. Reference range 2.20-2.60 mmolll (not indicated on figures for reasons of clarity). ${ }^{* * *} p<0.001$ from baseline; $0 p<0.01$ between groups.

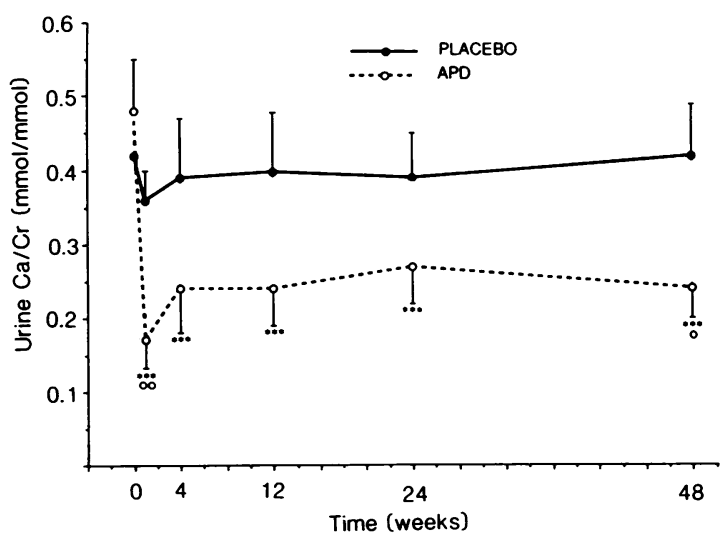

Fig. 2 Response of fasting urinary calcium/creatinine $(\mathrm{Ca} / \mathrm{Cr})$ ratio to treatment with aminohydroxypropylidene bisphosphonate (APD) and placebo. Reference range (mmol/mmol) <0.50. Points are means, bars SEM. ${ }^{* * *} p<0.001$ from baseline; $0 p<0.01$ between groups; ०० $p<0.001$ between groups. 
ist who was unaware of the patient's treatment ( $\mathrm{LH})$ and scored using the methods of Larsen $e t a^{12}$ and Sharp et al. ${ }^{13}$

The paired and unpaired Student's $t$ tests were used in statistical analysis of the data. Two tailed probabilities were used throughout.

\section{Results}

Table 1 shows the relevant clinical and laboratory variables in the study group. The two treatment groups were closely matched for disease activity as judged by clinical and laboratory criteria, age and sex distribution, disease duration, and penicillamine dose. There were no significant changes in any of the variables shown in Table 1 during the study, with the exception of articular index, which fell from

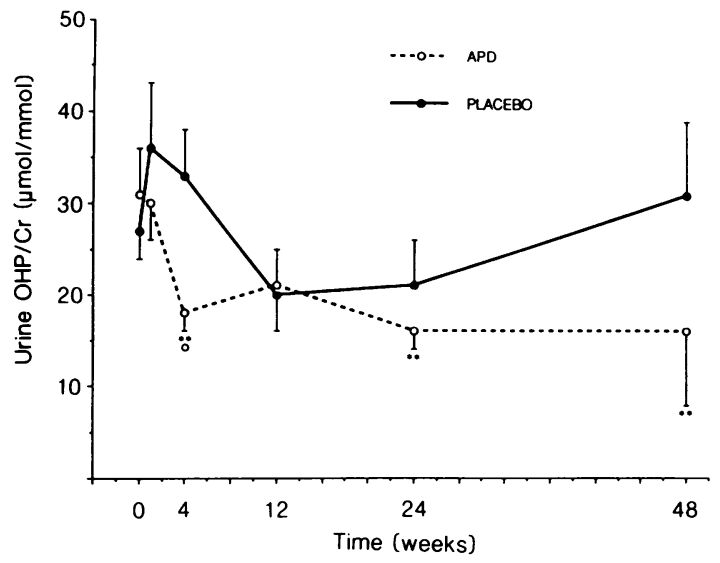

Fig. 3 Response of fasting urinary hydroxyproline/ creatinine $(O H P / C r)$ ratio to treatment with $(A P D)$ and placebo. Reference range $(\mu \mathrm{mol} / \mathrm{mmol})<30$. Points are means, bars SEM. ${ }^{* *} p<0.01$ from baseline; $\circ p<0.01$ between groups. (mean (SEM)) $13.8(1.8)$ to $7.2(2.2)$ in the APD ${ }^{\frac{0}{p}}$. group and from $13.7(1.9)$ to $6.8(1.5)$ in the placebo $\overrightarrow{\vec{s}}$ group (both significant; $\mathrm{p}<0.001$ ).

In the APD group there was a transient fall ine serum calcium one week after the initial infusion, $\frac{\bar{c}}{\frac{5}{2}}$ though by one month calcium values had returned too the pretreatment concentration and remained stable thereafter throughout the study period. Serums calcium did not change significantly in the placebo $\vec{P}$ group (Fig. 1).

Urinary calcium/creatinine fell significantly in the APD group from day 7 and remained suppressed throughout the study period. There were no significant changes in calcium/creatinine values in theos placebo group (Fig. 2).

Urinary hydroxyproline/creatinine values also felko in the APD group, the change being statisticallyo significant from one month onward. There was no change in hydroxyproline/creatinine values in the placebo group (Fig. 3).

The degree of radiological joint damage, asassessed by the methods of Larsen et $\mathrm{l}^{12}$ and Sharpos et $a^{13}$ was similar in both treatment groups at the beginning of the study. After 12 months radiologicab progression was noted in both groups using the Sharp method, whereas there was no significanto change in the Larsen scores (Table 2).

No side effects directly attributable to the APD $\mathbb{Q}$ were observed during the study, though progression $\vec{B}$ of pre-existing pulmonary fibrosis was noted at six 3 months in one patient treated with APD. This patient was an elderly man of 73 , who withdrew? from the study after two APD doses because of lacko of benefit and the inconvenience of having to attend $\overline{\mathrm{P}}$ for monthly intravenous infusions. At the time of withdrawal there was no clinical suspicion of progressive pulmonary disease. Transient flu like symp-O국 toms were observed in two patients treated with APD after the first infusion, but similar symptoms also occurred in three patients treated with placebo $\frac{D}{O}$

Table 2 Effects on radiological progression. Values are mean (SEM) and (range)

\begin{tabular}{|c|c|c|c|c|}
\hline & \multicolumn{2}{|l|}{$A P D^{\dagger}$} & \\
\hline & Before treatment & After treatment & Before treatment & After treatment \\
\hline $\begin{array}{l}\text { Sharp index } \\
\text { Larsen index }\end{array}$ & $\begin{array}{l}86(13 \cdot 1) \\
(14-193) \\
53(4 \cdot 2) \\
(26-82)\end{array}$ & $\begin{array}{l}95(12 \cdot 9)^{*} \\
(22-203) \\
57(3 \cdot 8) \\
(28-85)\end{array}$ & $\begin{array}{l}103(15 \cdot 1) \\
(8-269) \\
62(5 \cdot 8) \\
(11-103)\end{array}$ & $\begin{array}{l}110(15 \cdot 8)^{* * *} \\
(8-266) \\
63(5 \cdot 6) \\
(12-102)\end{array}$ \\
\hline \multicolumn{5}{|c|}{$\begin{array}{l}{ }^{*} \mathrm{p}<0.01 \text { from before treatment; }{ }^{* *} \mathrm{p}<0.02 \text { from before treatment. } \\
+\mathrm{APD}=\text { aminohydroxypropylidene bisphosphonate. } \\
\text { In the placebo group } 19 \text { pairs of radiographs were available for assessment before and after the study. In the APD group the three patients } \\
\text { who dropped out before six months were excluded from analysis, but } x \text { rays were analysed from one patient who dropped out after eigh } 19 \\
\text { months of APD, giving a total of } 17 \text { paired radiographs analysed. }\end{array}$} \\
\hline
\end{tabular}




\section{Discussion}

In the present study a single $30 \mathrm{mg}$ infusion of APD had a prolonged inhibitory effect on bone resorption as shown by the significant reduction in both calcium/ creatinine and hydroxyproline/creatinine ratios for up to 30 days. These findings concur with previous data in other clinical situations. ${ }^{5-9}$ Although the fall in hydroxyproline/creatinine ratio was less consistent than that of the calcium/creatinine ratio, this was probably owing to hydroxyproline release from sources other than bone. ${ }^{14}$

Despite the above biochemical response hand radiographs before and after 12 months showed no significant effect of APD progression of periarticular bone erosions. It is possible that the focal bone resorption associated with these lesions may either have been non-osteoclast mediated, ${ }^{15}$ and therefore resistant to the effects of APD, or have been too intense to be modified by the doses of APD used in the present study. In either event this focal bone resorption presumably contributed little to the sum total of bone resorptive activity going on throughout the skeleton. Thus the biochemical response probably reflected inhibition of bone resorption associated with more diffuse periarticular osteoporosis ${ }^{16}$ or even generalised osteoporosis, which appears to be more prevalent in rheumatoid arthritis. ${ }^{17}$ The standard radiological methods used to assess progression of erosive disease in this study would not have been sensitive enough to detect such changes in bone density. In future studies it would be interesting to obtain formal measurements of bone mineral content either in the spine or at the distal radius in patients undergoing bisphosphonate treatment. ${ }^{18}$

APD and other amino substituted bisphosphonates are known to cause flu like symptoms and a transient acute phase response in some individuals, particularly on initial administration, which may be due to stimulation of interleukin 1 release. ${ }^{19}$ Although such an effect could theoretically worsen rheumatoid arthritis and actually enhance bone resorption, patients treated with APD did not generally experience clinical symptoms consistent with such an effect, or show any greater an acute phase response than those treated with placebo. Indeed, APD treatment was well tolerated generally and had no detectable effect on disease activity.

In view of the biochemical evidence of an inhibitory effect on bone resorption, APD and similar bisphosphonates may be of value in the prevention and management of osteopenia associated with rheumatoid arthritis. Further studies are necessary both to define the precise effects on peripheral and axial bone density and to assess whether or not a different dose regimen or adminis- tration at an earlier stage in the disease could modify progression of periarticular erosive disease.

We thank Ciba Geigy Pharmaceuticals for kindly donating the APD (CGP 23339), and Mrs Dorothy McKnight for help with the statistical analysis.

\section{References}

1 Bywaters E G L. The early radiological signs of rheumatoid arthritis. Bull Rheum Dis 1960; 11: 231-4.

2 Fogelman I. Rheumatoid arthritis and osteoporosis. $\mathrm{Br} \mathrm{J}$ Rheumatol 1986; 25: 240-1.

3 Iannuzi L, Dawson N, Zein N, Kushner I. Does drug therapy slow radiographic deterioration in rheumatoid arthritis? $N$ Engl J Med 1983; 309: 1023-8.

4 Reid D M, Kennedy N S J, Smith M A, et al. Bone loss in rheumatoid arthritis and primary generalised osteoarthrosis: effects of corticosteroids, suppressive antirheumatic drugs and calcium supplements. Br J Rheumatol 1986; 25: 253-9.

5 Harinck H I J, Papapoulos S E, Blanksma H J, Moolenaar A J, Vermeij P, Bijvoet O L M. Paget's disease of bone: early and late responses to three different modes of treatment with aminohydroxypropylidene bisphosphonate (APD). $\mathrm{Br} \mathrm{Med} \mathrm{J}$ 1987; 295: 1301-5.

6 Ralston S H, Gardner M D, Dryburgh F J, Jenkins A S, Cowan $R$ A, Boyle I T. Comparison of aminohydroxypropylidene bisphosphonate, mithramycin and corticosteroid/calcitonin in treatment of cancer associated hypercalcaemia. Lancet 1985; ii: 907-10.

7 Van Breukelen F J M, Bijvoet O L M, Frijlink W B, Mulder H, Van Oosteroom A T. Efficacy of aminohydroxyproylidene bisphosphonate in hypercalcaemia-observations on regulation of serum calcium. Calcif Tissue Int 1982; 34: 321-7.

8 Reid I R, King A R, Alexander C J, Ibbertson H K. Prevention of steroid induced osteoporosis with (3-amino-l-hydroxypropylidene)-1,1,bisphosphonate (APD). Lancet 1988; i: 143-6.

9 van Holten-Verzantvoort A Th, Bijvoet O L M, Hermans J, et al. Reduced morbidity from skeletal metastases in breast cancer patients during long term bisphosphonate (APD) treatment. Lancet 1987; ii: 983-5.

10 Gardner M D, Dryburgh F J, Fyffe J A, Jenkins A S. Predictive value of derived calcium figures based on the measurement of ionised calcium. Ann Clin Biochem 1981; 18: 106-9.

11 Madhok R, Capell H A. Evaluation of drug response. In: Moll J M H, Bird H A, Rushton A, eds. Therapeutics in rheumatology. London: Chapman and Hall, 1986: 148-79.

12 Larsen A, Dale K, Eek M. Radiographic evaluation of rheumatoid arthritis and related conditions by standard reference films. Acta Radiol [Diagn] (Stockh) 1977; 18: 481-91.

13 Sharp J T, Young D Y, Bluhm G B, et al. How many joints in the hands and wrists should be included in a score of radiologic abnormalities used to assess rheumatoid arthritis? Arthritis Rheum 1985; 28: 1326-35.

14 Sambrook P N, Reeve J. Bone disease in rheumatoid arthritis. Clin Sci 1988; 74: 225-30.

15 Vernon Roberts B. Rheumatoid joint pathology revisited. In: Dick W C, Moll J M H, eds. Recent advances in rheumatology. Vol 3, Edinburgh: Churchill Livingstone, 1983: 73-95.

16 Sambrook P N, Ansell B M, Foster S, Gumpel J M, Hesp R, Reeve J. Bone turnover in early rheumatoid arthritis. 2. Longitudinal bone density studies. Ann Rheum Dis 1985; 44: $580-4$.

17 Compston J E, Crawley E O, Evans C, O’Sullivan M M. Spinal trabecular bone mineral content in patients with non-steroid treated rheumatoid arthritis. Ann Rheum Dis 1988; 47: 660-4.

18 Murby B, Fogelman I. Bone mineral measurements in clinical practice. Br J Hosp Med 1987; 37: 453-8.

19 Adami S, Bhalla A K, Dorrizi R, et al. The acute phase response after bisphosphonate administration. Calcif Tissue Int 1987; 41: 326-31. 